\title{
$\mathrm{HF}$ 데이터 통신에서 디지털 모뎀을 위한 \\ $\mathrm{RS}$ 및 컨볼루션 부호의 연접 부호 성능
}

\section{Performance of Concatenated Reed-Solomon and Convolutional Codes for Digital Modems in HF Data Communications}

\author{
김정창*, 양규식*, 정기룡*, 박동국*, 정성훈* \\ Jeong-Chang Kim, Gyu-Sik Yang*, Gi-Ryong Jeong ${ }^{*}$, Dong-Kook Park ${ }^{\star}$, and Sung-Hun Jung* \\ 요 약
}

본 논문에서는 HF (high frequency) 데이터 통신을 위한 디지털 모뎀의 성능 향상을 위하여 개선된 오류정정 부호 방식을 제안하고 성능을 검증한다. 제안하는 오류정정부호 방식은 외부의 Reed-Solomon 부호와 내부의 컨볼루션 부호를 연접하여 만들어진다. 시뮬레이션 결과는 제안하는 시스템이 기존 PACTOR-III 규격의 오류정 정부호 방식을 사용하는 시스템에 비해 비트 오율 성능을 크게 향상시킴을 보여준다. 따라서 제안하는 부호화 방식을 사용하여 HF 데이터 통신을 위한 디지털 모뎀의 대역폭 효율성을 크게 향상시킬 수 있을 것이다.

\section{Abstract}

In this paper, we propose an improved error correction code in order to improve the performance of digital modems for HF data communications and verify the performance of the proposed scheme. The proposed scheme employs outer Reed-Solomon codes concatenated with inner convolutional codes. Numerical results show that the proposed system significantly improves the bit error rate performance compared to the conventional PACTOR-III modems. Hence, the proposed system can improve the bandwidth efficiency of digital modems for $\mathrm{HF}$ data communications.

Key words : Concatenation, convolutional code, HF, PACTOR-III, Reed-Solomon

\section{I. 서 론}

ITU-R 권고안 M.1798-1에 따르면 MF/HF (medium frequency and high frequency) 대역에서 데이터 및 전 자메일을 위한 MMS (maritime mobile service)를 제공 하기 위하여 디지털 모뎀 기술의 사용이 고려되고 있 다 [1]. 이를 위하여 [1]에서는 물리계층 전송방식으 로 OFDM (orthogonal frequency division multiplexing)
을 이용한 $\mathrm{HF}$ 데이터 서비스 모뎀 프로토콜과 PACTOR-III 프로토콜이 제시되었다. 또한, HF 대역 에서 데이터 통신 서비스를 제공하기 위한 디지털 모 뎀 개발에 대한 연구가 많이 진행되고 있다 [1]-[3]. $\mathrm{HF}$ 데이터 통신을 위한 디지털 모뎀들 중 PACTORIII 프로토콜을 적용한 디지털 모뎀은 오류정정부호 로서 컨볼루션 부호 (convolutional code: $\mathrm{CC}$ )를 사용 하고 있다. 그러나 HF 대역 디지털 모뎀의 강건성 및

* 한국해양대학교 (Korea Maritime University)

· 제1저자 (First Author) : 김정창

· 교신저자 (Corresponding Author) : 양규식, 정기룡, 박동국, 정성훈

· 투고일자 : 2012년 1월 11일

심사(수정)일자 : 2012년 2월 10일 (수정일자 : 2012년 4월 9일)

· 게재일자 : 2012년 4월 30일 
대역폭 효율성을 더욱 높이고 모뎀 성능을 향상시키 기 위한 여지가 많이 남아 있는 실정이다.

본 논문에서는 PACTOR-III 모뎀의 물리계층 방식 및 이를 적용한 송수신기 구조에 대해서 간단히 소개 한다. 또한, HF 데이터 통신을 위한 디지털 모뎀의 성능 향상을 위하여 개선된 오류정정부호 방식을 제 안하고 시뮬레이션을 통하여 성능을 검증한다. 제안 하는 오류정정부호 방식은 외부의 Reed-Solomon (RS) 부호와 내부의 컨볼루션 부호를 연접하여 만들 어진다. 시뮬레이션을 통하여 제안하는 부호화 방식 이 기존 PACTOR-III 모뎀의 오류정정부호 방식인 컨 볼루션 부호에 비해 우수한 비트 오율 (bit error rate: $\mathrm{BER})$ 성능을 가짐을 확인할 수 있다. 따라서, 제안하 는 부호화 방식을 사용하여 HF 대역 디지털 모뎀의 대역폭 효율성을 크게 향상시킬 수 있을 것이다.

\section{PACTOR-III 물리계층 모뎀}

\section{2-1 PACTOR-III 물리계층 소개}

$\mathrm{HF}$ 데이터 통신을 위하여 제안된 기존의 PACTOR-III 모뎀은 다중 반송파 전송 방식을 사용하 며 [1]에 구체적인 전송 규격이 제시되어 있다. 각각 의 반송파는 부반송파 혹은 채널로 명명되며 각 채널 에 대해서 차동변조방식 (differential phase shift keying: DPSK)을 사용하여 데이터를 변조한다.

표 1은 PACTOR-III 모뎀의 전송 속도를 나타내는 스피드 레벨 (speed level: SL)에 따라 사용되는 채널 의 개수 및 채널 번호 (channel number: $\mathrm{CN}$ ), 그리고 각 채널이 차지하고 있는 주파수 (tone frequency: TF) 를 나타낸다. 스피드 레벨은 모두 6가지가 정의되며 모뎀이 동작하는 채널 상황에 따라 최소 2 개의 채널 부터 최대 18 개의 채널까지 선택적으로 사용될 수 있 다. 또한, 각 채널이 차지하는 대역폭은 $120 \mathrm{~Hz}$ 로 정 의된다.

표 2는 스피드 레벨에 따른 변조 방식, 컨볼루션 부호의 구속장 (constraint length: CL) 및 부호율 (code rate: $\mathrm{CR}$ ), 물리적 전송률 (physical data rate: PDR)을 나타낸다. 변조 방식으로는 스피드 레벨에 따라
DBPSK (differential binary phase shift keying)와 DQPSK (differential quadrature phase shift keying)가 사 용된다. 각 채널에서 초당 100 개의 변조 심벌들이 전 송되며 사용되는 채널의 개수와 변조 방식에 따라 해 당 스피드 레벨의 $\mathrm{PDR}$ 은 다음과 같이 결정된다.

$$
P D R=100 \times N_{c h} \times \log _{2} M \quad[b p s]
$$

여기서, $N_{c h}$ 는 사용되는 채널의 개수를 나타내고, $M$ 은 변조 차수를 나타낸다. 예를 들어, $\mathrm{SL}=1$ 인 경우 $M=2$ 이고 $\quad N_{c h}=2$ 이므로 $\quad P D R=200$ 이다. $\mathrm{SL}=4$ 인 경우 $\quad M=4$ 이고 $N_{c h}=14$ 이므로 $P D R=2800$ 이다.

표 1. 스피드 레벨에 따라 사용되는 채널의 개수 및 위치 Table 1. Number and position of the used channels for different SLS.

\begin{tabular}{|c|c|c|c|c|c|c|c|}
\hline \multirow{2}{*}{$\mathrm{CN}$} & \multicolumn{6}{|c|}{ SL } & \multirow{2}{*}{$\mathrm{TF}$} \\
\hline & 1 & 2 & 3 & 4 & 5 & 6 & \\
\hline 0 & & & & & & 0 & 480 \\
\hline 1 & & & & & 0 & 0 & 600 \\
\hline 2 & & & 0 & 0 & 0 & 0 & 720 \\
\hline 3 & & 0 & 0 & 0 & 0 & 0 & 840 \\
\hline 4 & & & 0 & 0 & 0 & 0 & 960 \\
\hline 5 & 0 & 0 & 0 & 0 & 0 & 0 & 1080 \\
\hline 6 & & & 0 & 0 & 0 & 0 & 1200 \\
\hline 7 & & 0 & 0 & 0 & 0 & 0 & 1320 \\
\hline 8 & & & 0 & 0 & 0 & 0 & 1440 \\
\hline 9 & & & 0 & 0 & 0 & 0 & 1560 \\
\hline 10 & & 0 & 0 & 0 & 0 & 0 & 1680 \\
\hline 11 & & & 0 & 0 & 0 & 0 & 1800 \\
\hline 12 & 0 & 0 & 0 & 0 & 0 & 0 & 1920 \\
\hline 13 & & & 0 & 0 & 0 & 0 & 2040 \\
\hline 14 & & 0 & 0 & 0 & 0 & 0 & 2160 \\
\hline 15 & & & 0 & 0 & 0 & 0 & 2280 \\
\hline 16 & & & & & 0 & 0 & 2400 \\
\hline 17 & & & & & & 0 & 2520 \\
\hline
\end{tabular}

표 2. 스피드 레벨에 따른 시스템 파라미터

Table 2. System parameters for different SLs.

\begin{tabular}{|c|c|c|c|c|}
\hline SL & Modulation & CL & CR & PDR \\
\hline 1 & DBPSK & 9 & $1 / 2$ & 200 \\
\hline 2 & DBPSK & 7 & $1 / 2$ & 600 \\
\hline 3 & DBPSK & 7 & $1 / 2$ & 1400 \\
\hline 4 & DQPSK & 7 & $1 / 2$ & 2800 \\
\hline 5 & DQPSK & 7 & $3 / 4$ & 3200 \\
\hline 6 & DQPSK & 7 & $8 / 9$ & 3600 \\
\hline
\end{tabular}

PACTOR-III 모뎀은 오류정정부호로서 컨볼루션 부호를 사용하고 있으며 표 2에서 나타나듯이 스피 
드 레벨에 따라 7 혹은 9 의 구속장과 $1 / 2,3 / 4,8 / 9$ 의 부호율을 갖는다. 스피드 레벨 5 와 6 에서 사용되는 부호율 $3 / 4,8 / 9$ 의 컨볼루션 부호는 부호율 $1 / 2$ 인 컨 볼루션 부호를 천공하여 사용한다.

\section{2-2 송수신기 구조}

그림 1은 PACTOR-III 프로토콜에서 물리계층 모 뎀용 송신기의 구조를 나타낸다. 그림 1 에서 컨볼루 션 부호에 의해 채널 부호화된 비트들은 인터리버에 서 비트 인터리빙된 후 변조기에서 DBPSK 혹은 DQPSK 방식으로 변조된다. 다음으로 변조된 심벌들 은 각 채널로 맵핑되기 이전에 펄스 성형 필터에 의 해서 필터링된다.

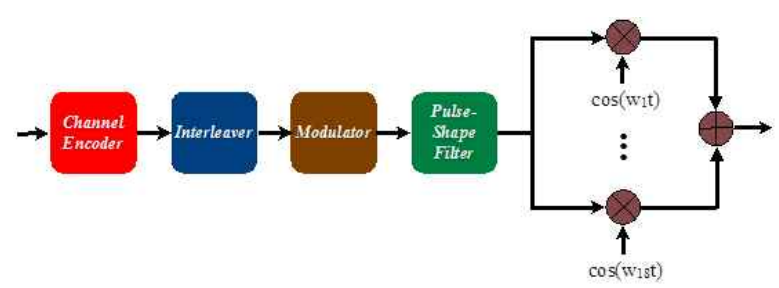

그림 1. PACTOR-III 프로토콜에서 물리계층 모뎀용 송신기의 블록도

Fig. 1. Block diagram of the transmitter for PHY modems in PACTOR-III protocol.
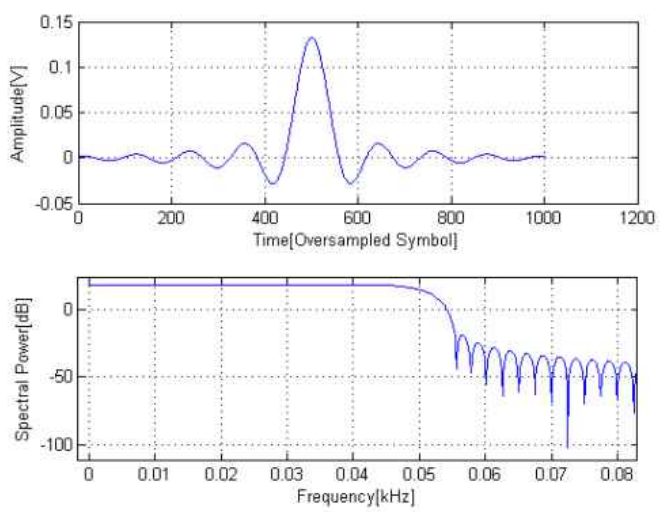

그림 2. 펄스 성형 필터의 임펄스 응답 및 스펙트럼 응답

Fig. 2. Impulse and spectrum responses of the pulse shape filter.

그림 2는 펄스 성형 필터의 임펄스 응답 및 스펙트 럼 응답을 나타낸다. 본 논문에서 펄스 성형 필터는 롤 오프 율 $\alpha=0.1$ 인 SRRC (squared-root raised cosine) 필터를 설계하여 사용했으며 통과대역은 각 채널의 PDR에 해당하는 $100 \mathrm{~Hz}$ 의 대역폭을 가지도 록 설계했다. 펄스 성형 필터를 거친 후 $100 \mathrm{~Hz}$ 의 대 역폭을 가지는 기저대역 신호를 표 1 에서 주어진 각 채널의 중심 주파수 $w_{i}=2 \pi f_{i}(i=1,2, \cdots, 18)$ 로 천이시킨 후 모두 더하여 최종 송신 신호를 생성한 다.

그림 3은 PACTOR-III 프로토콜에서 물리계층 모 뎀용 수신기의 구조를 나타낸다. 수신 신호로부터 중 심 주파수 $w_{i}=2 \pi f_{i}(i=1,2, \cdots, 18)$ 를 갖는 채 널을 각각 추출한 후 해당 변조방식에 대한 연판정 값을 계산한다. 각 채널에 대한 정합필터는 송신기 펄스 성형 필터와 동일한 SRRC 필터를 사용하였다. 연판정 값은 정합필터 출력 값으로부터 LLR (log-likelihood ratio) 값을 계산함으로써 얻을 수 있다.

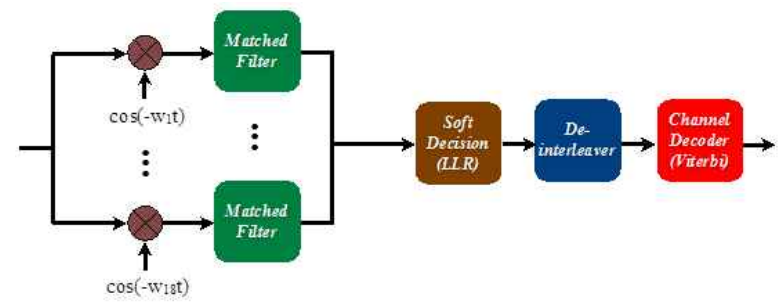

그림 3. PACTOR-III 프로토콜에서 물리계층 모뎀용 수신기의 블록도

Fig. 3. Block diagram of the receiver for PHY modems in PACTOR-III protocol.

본 논문에서는 DBPSK를 사용하는 스피드 레벨 1 , 2,3 에 초점을 두고 송수신기를 구현하였다. DBPSK 변조방식에 대한 LLR 값은 다음과 같이 얻을 수 있 다 [2], [3].

$$
L_{k}=\frac{2 E_{S} \operatorname{Re}\left\{r_{k} r_{k-1}^{*}\right\}}{\sigma^{2}}
$$

$$
L_{k}=\frac{2 \sqrt{E_{S}}}{N_{0}}\left(\left|r_{k}+r_{k-1}\right|-\left|r_{k}-r_{k-1}\right|\right)(3)
$$

여기서, $E_{S}$ 는 심벌 당 평균 에너지, $N_{0} / 2$ 는 가산 백색 가우시안 잡음 (additive white Gaussian noise: $\mathrm{AWGN)}$ 의 전력밀도, $\sigma^{2}$ 는 잡음의 분산을 나타낸다. 
또한, $r_{k}$ 는 정합 필터 출력의 $k$ 번째 신호를 나타낸 다.

수식 (2)의 경우 DBPSK에 대한 결정 메트릭 $\operatorname{Re}\left\{r_{k} r_{k-1}^{*}\right\}$ 의 통계적 특성이 가우시안 분포를 따 른다고 가정하고 계산된 LLR 값이다 [4], [5]. 그러나 실제로 $\operatorname{Re}\left\{r_{k} r_{k-1}^{*}\right\}$ 의 통계적 특성은 가우시안 분 포와 차이가 있으므로 (2)의 결정 메트릭은 성능 열 화를 유발시킨다. 이를 개선하기 위하여 [5]에서 보 다 정확한 LLR 계산식이 유도되었으며 (3)과 같이 주 어진다. 본 논문에서는 (3)과 같이 계산된 LLR 값을 사용한다.

다음으로 계산된 LLR 값들에 대해서 송신기 인터 리빙의 역변환에 해당하는 디인터리빙을 수행하고 Viterbi 디코더에서 디코딩을 수행하여 원래의 비트 들을 복원한다.

\section{III. 제 안하는 시스템}

PACTOR-III 모뎀은 오류정정부호로서 컨볼루션 부호를 사용하고 있으나 개선의 여지가 많이 남아 있 다. 본 논문에서는 HF 데이터 통신을 위한 디지털 모 뎀에서 컨볼루션 부호에 RS 부호를 외부 부호로 연 접한 연접 부호화 방식을 제안한다. 제안하는 방식은 기존 PACTOR-III 모뎀에 비해 비트 오율 성능을 향 상시키고 대역폭 효율성을 증대시킬 수 있다.

그림 4는 HF 데이터 통신에서 컨볼루션 부호와 연 접된 RS 부호를 사용하는 디지털 모뎀을 위한 송수 신기의 블록도를 나타낸다. 그림 4 에서 볼 수 있듯이 송신기의 컨볼루션 인코더 앞단에 RS 인코더를 연접 하였다. 제안하는 시스템에서 사용된 RS 부호는 $\mathrm{GF}(256)$ 상에서 설계되었으며 RS 부호 파라미터들 $n, k, t$ 는 각각 $\mathrm{RS}$ 인코더의 입력 심벌 길이, $\mathrm{RS}$ 인 코딩된 부호 심벌 길이, 오류정정 능력을 나타낸다. 따라서 제안하는 시스템에서 최종 부호율은 $C R \times \frac{k}{n}$ 와 같이 주어진다. 또한 본 논문에서는 $\mathrm{GF}(256)$ 상에서 설계된 RS 부호를 사용하고 있으므 로 하나의 RS 입력 심벌 혹은 부호 심벌은 8 비트로 구성된다.

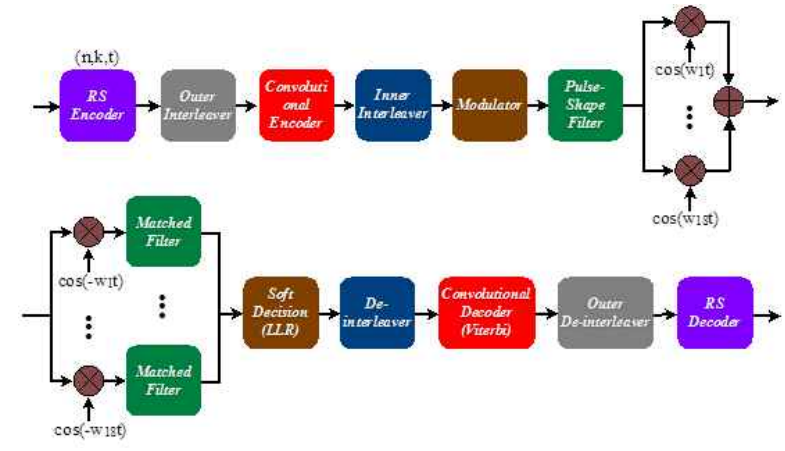

그림 4. HF 데이터 통신에서 컨볼루션 부호와 연접된 외부 RS 부호를 사용하는 디지털 모뎀을 위한 송수신기의 블록도

Fig. 4. Block diagram of the transmitter and receiver for digital modems employing outer RS codes concatenated with convolutional codes in HF data communications.

먼저, $8 k$ 비트의 정보 비트들을 8 비트씩 묶어 $k$ 개 의 RS 입력 심벌을 생성한 후 RS 인코더에서 인코딩 을 수행한다. 본 논문에서 사용한 RS 부호의 파라미 터 $(n, k, t)$ 는 $(63,55,4)$ 와 같다.

다음으로 RS 인코딩된 부호 심벌들에 대해서 외 부 인터리버에서 인터리빙을 수행한 후 RS 부호 심 벌들은 비트 열로 변환된다. 변환된 비트 열은 컨볼 루션 인코더로 입력되어 컨볼루션 부호화된다. 제안 하는 시스템에서 컨볼루션 부호는 PACTOR-III 모뎀 에서와 동일한 $\mathrm{CL}=7, \mathrm{CR}=1 / 2$ 인 컨볼루션 부호를 사 용한다. 컨볼루션 부호화된 비트들은 내부 인터리버 에 의해서 인터리빙된다. RS 부호 파라미터 $(63,55,4)$ 에 대한 부호율은 대략 0.873 이고 컨볼루 션 부호의 부호율은 $1 / 2$ 이므로 연접부호의 최종 부 호율은 대략 0.4365 의 값을 가진다.

제안하는 시스템에서는 DQPSK 변조방식을 사용 하고 $\mathrm{SL}=3$ 인 경우와 동일한 14 개의 주파수 톤을 사 용한다. 그러면, 내부 인터리버에 의해서 인터리빙된 비트들은 DQPSK 변조된 후 펄스 성형 필터로 입력 되고 14 개의 주파수 톤을 사용하여 전송된다.

제안하는 시스템의 수신기에서 컨볼루션 디코더 까지는 기존 PACTOR-III 모뎀과 동일하게 동작한다. 제안하는 시스템에서는 DQPSK 변조방식을 사용하 므로 수신기에서 DQPSK 변조방식에 대한 연판정 값 계산이 필요하다. $\mathrm{DQPSK}$ 변조방식에 대한 연판정 LLR 값은 다음과 같이 얻을 수 있다 [6], [7]. 


$$
\begin{aligned}
L_{k, M S B}= & \frac{2 \sqrt{E_{S}}}{N_{0}} \times \\
& \max _{\Delta \phi_{k}=\frac{\pi}{4}, \frac{3 \pi}{4}} r_{k}+r_{k-1} e^{j \Delta \phi_{k}} \\
& -\max _{\Delta \phi_{k}=\frac{-\pi}{4}, \frac{-3 \pi}{4}} r_{k}+r_{k-1} e^{j \Delta \phi_{k}} \\
L_{k, L S B}= & \frac{2 \sqrt{E_{S}}}{N_{0}} \times \\
& \max _{\Delta \phi_{k}= \pm \frac{\pi}{4}} r_{k}+r_{k-1} e^{j \Delta \phi_{k}} \\
& -\max _{\Delta \phi_{k}= \pm \frac{3 \pi}{4}} r_{k}+r_{k-1} e^{j \Delta \phi_{k}}
\end{aligned}
$$

여기서, $L_{k, M S B}$ 와 $L_{k, L S B}$ 는 각각 정합 필터 출력 의 $k$ 번째 $\mathrm{DQPSK}$ 심벌 값에 대한 상위 비트와 하위 비트의 LLR 값을 나타낸다.

다음으로 Viterbi 디코딩을 수행한 이후에 외부 디 인터리버는 송신기 외부 인터리빙의 역변환에 해당 하는 디인터리빙을 수행하고 RS 디코더에서 원래의 비트들이 복원된다.

\section{IV. 시뮬레이션 결과}

본 논문에서는 제안하는 시스템의 성능을 시뮬레 이션을 통하여 검증하고 기존 PACTOR-III 모뎀의 성 능과 비교한다. PACTOR-II에서 지원하는 6가지 스 피드 레벨들 중에서 DBPSK 변조방식을 사용하는 $\mathrm{SL}=1,2,3$ 을 고려한다. 본 논문에서 $\mathrm{CL}=9,7$ 인 컨볼 루션 인코더의 생성 다항식은 각각 $(561,753)$ 와 $(133$, 171)을 사용했다 [8]. 또한, 제안하는 시스템에서 사 용하는 RS 부호의 알파벳 사이즈는 8 로 정하였고 RS 부호 파라미터는 $(n, k, t)=(63,55,4)$ 와 같다. 즉, $\mathrm{RS}$ 인코더의 입력 심벌 길이는 55 이고 인코딩된 부호 심벌 길이는 63 , 오류정정 능력은 4 이다. 시뮬레 이션에서 송수신기 사이의 채널은 $\mathrm{AWGN}$ 채널을 가 정하였다. 제안하는 시스템과 기존 PACTOR-III 모뎀 의 성능 비교를 위하여 평균 비트 오율 및 normalized throughput 성능을 비교하였다.

그림 5 는 제안하는 시스템 및 기존 PACTOR-III 모 뎀 방식의 평균 비트 오율 성능을 보여준다. 기존
PACTOR-III 모뎀은 컨볼루션 부호만 사용하고 있으 며 $\mathrm{SL}=2$ 와 $\mathrm{SL}=3$ 은 변조방식, $\mathrm{CL}, \mathrm{CR}$ 값이 동일하므 로 그림 5에서 볼 수 있듯이 동일한 비트 오율 성능 을 나타낸다. 반면, $\mathrm{SL}=1$ 인 경우 $\mathrm{CL}=9, \mathrm{CR}=1 / 2$ 로서 $\mathrm{SL}=2,3$ 인 경우에 비해 더 나은 비트 오율 성능을 보 인다.

제안하는 시스템의 경우 $\mathrm{SL}=3$ 인 PACTOR-III 모뎀 과 컨볼루션 부호 파라미터 및 사용하는 채널의 수가 동일하도록 설정했으며 변조방식은 $\quad \mathrm{SL}=3$ 인 PACTOR-III 모뎀보다 2배 높은 변조차수를 갖는 DQPSK 변조방식을 사용했다. 제안하는 시스템은 대 략 $\mathrm{SNR}=5.5 \mathrm{~dB}$ 이상에서 기존 PACTOR-III 모뎀의 $\mathrm{SL}=2,3$ 보다 향상된 비트 오율 성능을 보여주며 $\mathrm{SNR}$ 이 증가할수록 성능 향상 정도는 더욱 증가한다. 또 한, $\mathrm{SL}=1$ 인 PACTOR-III 모뎀과 비교했을 때 $\mathrm{SNR}=6$ $\mathrm{dB}$ 이상에서 보다 우수한 평균 비트 오율 성능을 나 타낸다. 특히, 모뎀의 동작 영역인 $\mathrm{BER}=10^{-6}$ 이하 에서 제안하는 시스템의 SNR 이득은 더욱 향상됨을 알 수 있다.

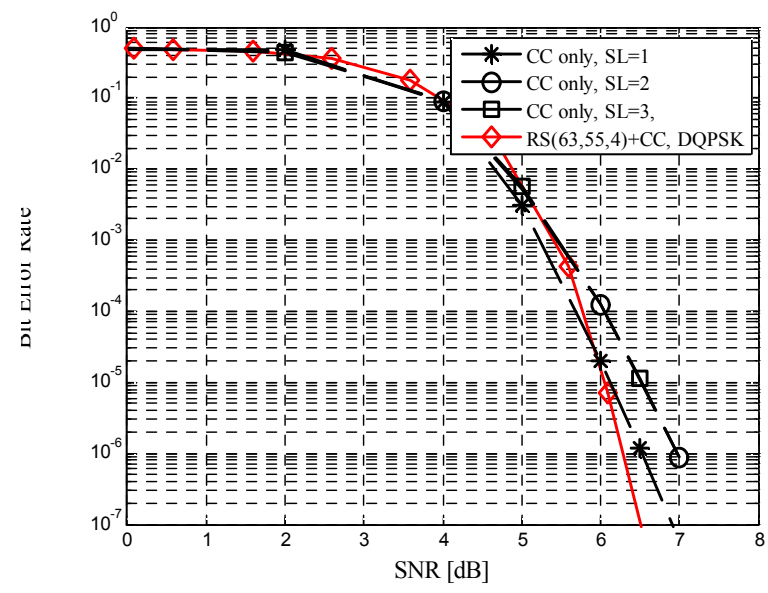

그림 5. 제안하는 부호화 방식 및 기존 PACTOR-III 모뎀 방식의 평균 비트 오율 성능 비교

Fig. 5. Average bit error rate performance of the proposed system and the conventional PACTOR-III modem.

그림 5에서 BER 성능을 비교하고 있으나 제안하 는 시스템 및 기존 PACTOR-III 모뎀은 사용하는 주 파수 대역폭과 전송률이 다르므로 단순한 비트 오율 성능의 비교만으로는 정당한 성능 비교가 되지 못한 
다. 따라서, 보다 정당한 성능 비교를 위하여 normalized throughput 관점에서 제안하는 시스템과 기존 PACTOR-III 모뎀의 성능을 비교한다. Normalized throughput은 단위 시간당 단위 주파수당 성공적으로 전송한 비트 수를 의미하며 다음과 같이 계산된다.

$$
W=\frac{C R \cdot P_{C} \cdot P D R}{B} \cdot \frac{k}{n}[\text { bits } / \mathrm{sec} / H z]
$$

여기서, $P_{C}=1-P_{b}$ 이고 $P_{b}$ 는 비트 오율을 나 타낸다. 또한, $B$ 는 주파수 대역폭을 나타낸다. 제안 하는 시스템의 PDR은 식 (1)과 마찬가지로 다음과 같이 계산될 수 있다.

$$
P D R_{R S / C C}=100 \times N_{c h} \times \log _{2} M
$$

사용되는 채널의 개수는 14 개, 변조차수는 4 이므 로 $P D R_{R S / C C}=2800$ 이다. 기존 PACTOR-III 모뎀 의 경우 normalized throughput은 RS 부호가 사용되지 않으므로 $\frac{C R \cdot P_{C} \cdot P D R}{B}$ 와 같이 계산된다.

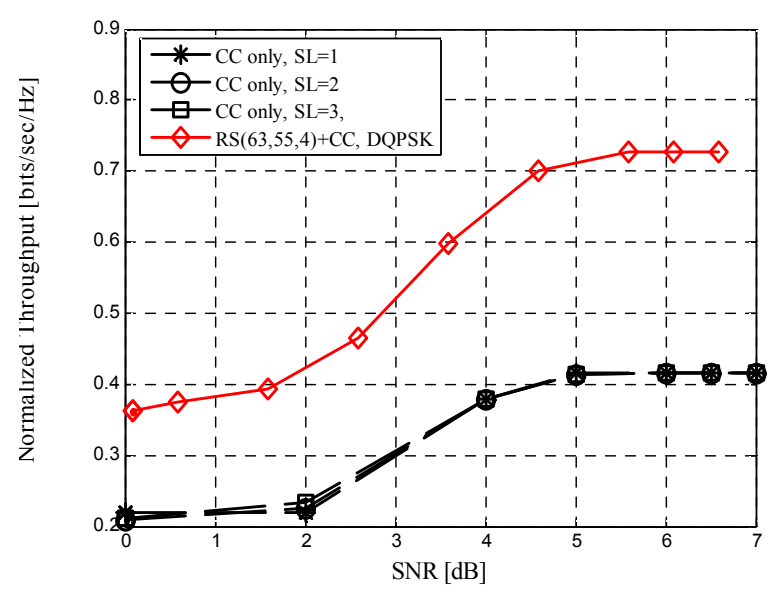

그림 6. 제안하는 부호화 방식 및 기존 PACTOR-III 모뎀 방식의 normalized throughput 비교

Fig. 6. Comparison of the normalized throughput for the proposed system and the conventional PACTOR-III modem.

그림 6 은 제안하는 시스템과 기존 PACTOR-III 모 뎀의 normalized throughput 성능 비교를 나타낸다. 제 안하는 시스템과 기존 PACTOR-III 모뎀 모두 SNR이
증가할수록 normalized throughput이 증가하는 것을 알 수 있다. 또한, 기존 PACTOR-III 모뎀의 $\mathrm{SL}=1,2$, 3 인 경우 normalized throughput은 모두 동일함을 알 수 있다. 제안하는 시스템은 기존 PACTOR-III 모뎀 에 비해 훨씬 높은 normalized throughput을 나타낸다. 특히, 모뎀의 동작 영역인 $\mathrm{BER}=10^{-6}$ 이하에 해당하 는 $\mathrm{SNR}=6 \mathrm{~dB}$ 이상의 $\mathrm{SNR}$ 영역에서 제안하는 시스템 이 기존 PACTOR-III 모뎀에 비해 1.75 배 가량의 throughput 향상을 보인다. 따라서 제안하는 시스템은 기존 PACTOR-III 모뎀에 비해 대역폭을 보다 효율적 으로 사용함을 알 수 있다.

\section{$\mathrm{V}$. 결 론}

본 논문에서는 HF 데이터 통신을 위한 디지털 모 뎀의 성능을 향상을 위하여 컨볼루션 부호와 연접된 $\mathrm{RS}$ 부호를 사용하는 시스템을 제안하였다. 제안하는 시스템은 기존의 PACTOR-III 모뎀에 비하여 동일한 채널 개수를 사용하면서 우수한 비트 오율 성능과 높 은 데이터 전송률을 지원할 수 있으므로 대역폭 효율 성을 증대시킬 수 있다. 향후 모든 채널을 사용하는 $\mathrm{SL}=6$ 에 대해서 제안하는 부호화 방식 및 고효율의 변조방식을 함께 적용함으로써 대역폭 효율성을 더 욱 향상시킬 수 있을 것으로 기대된다.

\section{감사의 글}

본 논문은 2011년도 부산테크노파크의 “지방과학 연구단지육성사업 R\&D 역량강화지원" 사업의 지원 비로 수행되었음.

\section{참 고 문 헌}

[1] Characteristics of HF radio equipment for the exchange of digital data and electronic mail in the maritime mobile service, Recommendation ITU-R M.1798-1, April 2010.

[2] A. R. M. Sidek and A. Z. Sha'ameri, "Evaluation of 
modulation coding schemes for adaptive HF data communication system," in Proc. of IEEE 2008 6th National Conference on Telecommunication Technologies and IEEE 2008 2nd Malaysia Conference on Photonics, pp. 267-272, Aug. 2008.

[3] G. Dimic, N. Nenadic and M. Nikolic, "Symbol and frame timing estimation for multicarrier HF packet radio," 17th Telecommunications forum TELFOR 2009, pp. 608-611, Nov. 2009.

[4] H. Tatsunami, K. Ishibashi, and H. Ochiai, "On the performance of LDPC codes with differential detection over Rayleigh fading channels," in Proc. of IEEE Veh. Technol. Conf., pp. 2388-2392, May 2006.

[5] E. Mo and P. Y. Kam, "Log-likelihood metrics based on two-symbol-interval observations for LDPC codes with BDPSK transmission," in Proc. of IEEE Veh. Technol. Conf., Sept. 2008.

[6] E. Mo P. Y. Kam, and M. A. Armand, "LLR metrics for LDPC codes with quadrature differential PSK transmission, and their performances," in Proc. of International Symp. Info. Theory and its App., Dec. 2008.

[7] E. Mo and M. A. Armand, "Pseudocodeword weights for LDPC codes under differential PSK transmission over the noncoherent AWGN channel," IEEE Trans. Commun, vol. 59, no. 5, pp. 1218-1223, May 2011.

[8] Y. Jiang, A practical guide to error-control coding using MATLAB, Artech House, 2010.

\section{김 정 창 (金廷昌)}

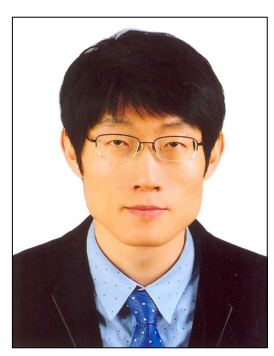

2000년 2월 : 한양대학교 전자전자통신. 전파공학과군 (공학사) 2002년 2월 : 포항공과대학교 전자 컴퓨터공학부 (공학석사) 2006년 8월 : 포항공과대학교 전자 컴퓨터공학부 (공학박사) 2010년 9월 현재 : 한국해양대학교 공과대학 전자통신공학과 전임강사 관심분야 : $\mathrm{MIMO}, \mathrm{OFDM}$, 디지털 통신시스템, 통신공학
양 규 식 (梁圭植)

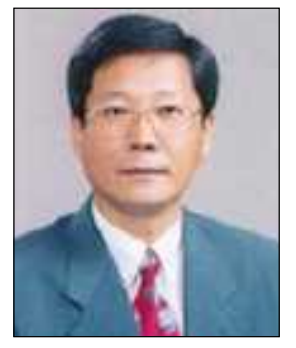

1974년 2월 : 한국항공대학교 통신 공학과(공학사)

1984년 2월 : 건국대학교 전자공학과 (공학석사)

1991년 2월 : 건국대학교 전자공학과 (공학박사)

1995년 3월 현재 : 한국해양대학교

공과대학 전자통신공학과 교수

관심분야 : e-navigation, 해상통신시스템, 안테나공학

\section{정 기 룡 (鄭起龍)}

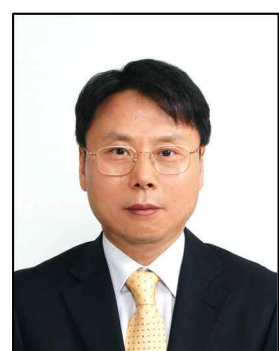

1983년 2월 : 한국항공대학교 통신 공학과(공학사)

1989년 2월 : 동아대학교 대학원 전자공학과(공학석사) 1997년 2월 : 동아대학교 대학원 전자공학과(공학박사)

1988년 3월 현재 : 한국해양대학교

해사대학 항해학부 교수

관심분야 : e-navigation, 해상통신시스템, 신호처리

박 동 국 (朴東國)

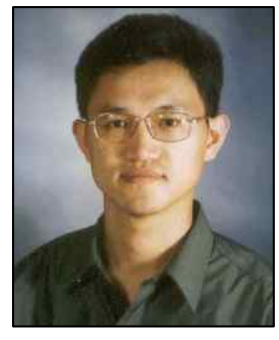

1987년 2월 : 부산대학교 전자공학과 (공학사)

1989년 2월 : KAIST 전기및전자공학과 (공학석사)

1994년 8월 : KAIST 전기및전자공학과 (공학박사)

1996년 4월 현재 : 한국해양대학교

공과대학 전자통신공학과 교수

관심분야 : 안테나공학, 무선전력전송, 초고주파공학

\section{정 성 훈 (鄭聖勳)}

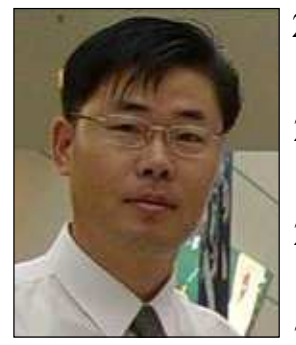

2002년 2월 : 동명정보대학교 컴퓨터 공학과(공학사)

2004년 2월 : 한국해양대학교 전자 통신공학과(공학석사)

2007년 2월 : 한국해양대학교 전자 통신공학과(공학박사)

2003년 3월 현재 : 한국해양대학교

산업기술연구소 산학연구교수

관심분야 : e-navigation, 해상통신시스템, IT convergence 